\title{
DFPI-based Control of the DC-bus Voltage and the AC- side Current of a Shunt Active Power Filter
}

\author{
Nabil Elhaj ${ }^{\star 1}$, M. Brahim Sedra ${ }^{2}$, Hind Djeghloud ${ }^{3}$ \\ ${ }^{1,2}$ Engineer Sciences \& Modeling Laboratory, Ibn Tofail University, Kenitra, Morocco \\ ${ }^{3}$ Laboratory of Electrical Engineering, Constantine 1 University, Constantine, Algeria \\ *Corresponding author, e-mail: Nabil.elhaj@uit.ac.ma
}

\begin{abstract}
The current paper presents a continuation of an earlier research and purposes to enhance the performances of the studied system. While the double fuzzy PI (DFPI) control was applied only on the DC capacitor bus in a previous work it is applied here also on the output current of shunt active power filter (SAPF). The nonlinear load disrupts the electrical distribution system by the generation of harmonics, which requires an efficient SAPF intervention to minimize the effects of harmonics on the network and provide electrical energy conforms to international standards. The design and simulation of this work were performed under MATLAB/Simulink environment. The carried-out simulation results demonstrate a satisfactory regulation both for the output current of the SAPF and the DC bus voltage. Furthermore the power quality is improved since a near-unity power factor and very low rates of imbalance of both source voltages and currents are obtained.
\end{abstract}

Keywords: SAPF, DFPI-based control, PSF algorithm, intersective PWM modulator, power quality improvement

\section{Introduction}

The quality and pollution of the power distribution systems is one of the research subjects which knows in recent years an important scientific advancement considering the progressive requests of electrical power especially the strategic choice of renewable energy as the main source of electrical power in the future. Using nonlinear loads is the principal source of harmonics currents; these are the main causes of the electrical power quality degradation. Harmonic currents produce approximately a $10 \%$ increase in voltage, that effect on the temperature of the devices per increased by $7 \%$, which reduces the duration of lifetime to $30 \%$ of such devices [1-3].

Shunt active power filters (SAPFs) [4] are the most efficient solution to current problems (harmonic currents, increasing neutral current, unbalanced currents, poor power factor...) which significantly contributes in the improvement of the quality of the delivered power that respects the recommendations and international standards [5], [8]. SAPFs are largely based on PWM voltage source or current source DC/AC converters (VSC/CSC), nevertheless current-source topology have weaknesses compared to voltage-source ones, such as high on-state losses in the PWM bridge and inefficient inductive energy storage element on the DC-bus [9].

Various strategies of controlling SAPFs are proposed and implemented in purpose of reaching near perfect quality of filtering [10]. The control system of a SAPF includes four main blocks: the regulator of the DC-bus capacitor voltage or inductor current, the algorithm of extraction of reference signals, the regulator of the AC-side current and the modulator that derives the gating signals to the SAPF electronic switches. Each one among the aforementioned blocks should be accurately designed to avoid poor compensation of the harmonic currents. One can find numerous techniques of regulation and reference signals extraction in the literature [11-12], [13-15]. Furthermore, investigation on more sophisticated techniques constitutes a field of a great interest.

The operation of the SAPF can be more optimized by a good dimensioning of the passive devices completing the filtering system namely the DC capacitor or the inductor bank which serves to feed the SAPF with a sufficient and a non-fluctuating DC voltage (Vdc) and the 
output filter which acts as a low-pass filter that mitigates high frequency harmonic components caused by the applied gating signals modulator [16].

The work addressed in this paper is a continuation of previous contributions [16-17] where the Double Fuzzy control [18] was associated to a PI controller resulting in a new regulator so-called 'DFPl' which aim was to obtain better control of ' $V d c$ ' by beneficiating from both double fuzzy and PI controllers advantages. The design of the PI controller was performed on the basis of the open loop of the corrected system transfer function. In this work, the DFPI control is extended to the AC-side current of the SAPF targeting to reduce the THD by providing a near perfect follow-up of the reference signal. The design of the PI controllers of both DC voltage and AC current of the SAPF is achieved on the basis of the closed loop of the system transfer function [19-20]. The positive sequence of the fundamental source voltage method (PSF) [21] is applied for the current reference signals extraction and the intersective PWM modulator is used to generate the gating signals.

\section{The Proposed Sapf System Description}

Figure 1 depicts the system to be filtered using the proposed SAPF. It is composed of a balanced three-phase power supply defined by its phase-to-neutral given voltage Vs and its internal impedance (Rs, Ls), a non-linear load that generates harmonics through a diode bridge feeding an inductive circuit (RL, LL), a shunt active power filter based on an IGBTs VSC, an inductive output filter (Rf, Lf) and an upstream filter (Rc, Lc). Roles and dimensioning of each component are available in [16].

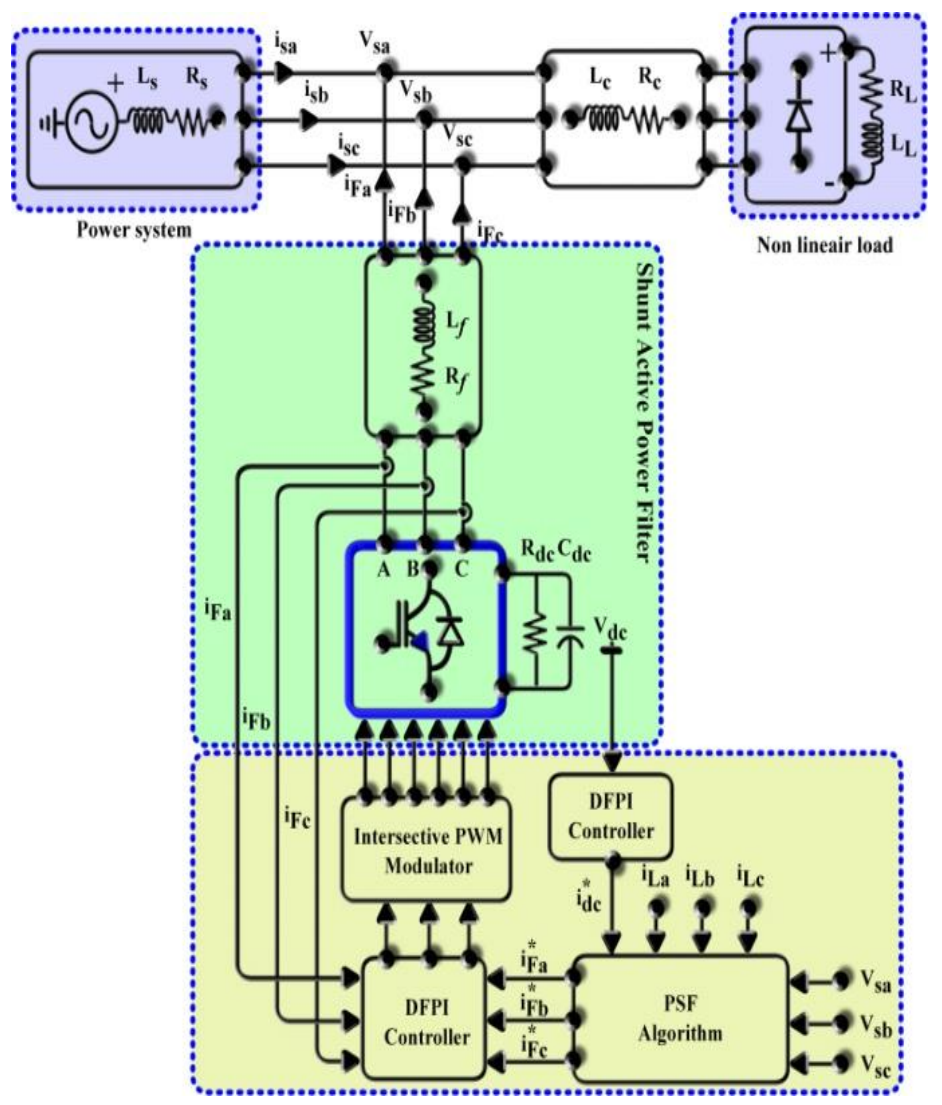

Figure 1. Scheme of the power system to be filtered using the proposed SAPF

\section{Sapf Control Circuit}

As mentioned previously, the control circuit is composed of four main blocks as schematized in Figure 2. 


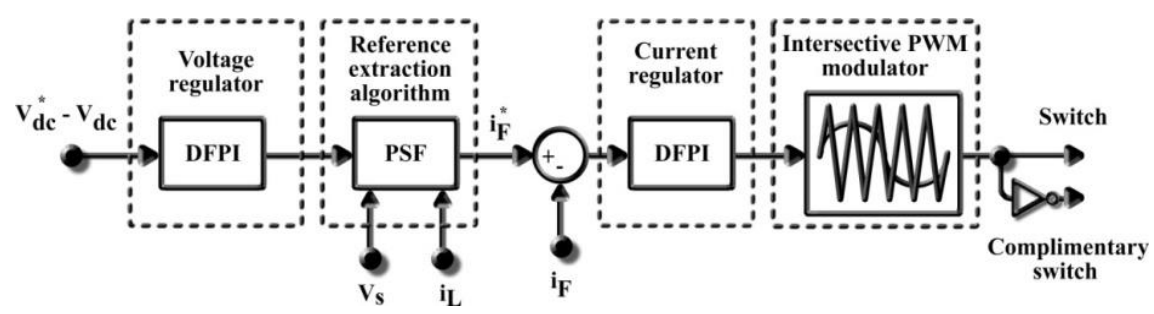

Figure 2. Synoptic scheme of the proposed DFPI controller for regulating the SAPF DC Voltage and $\mathrm{AC}$ current

The principle of the DFPI controller is illustrated in Figure 3 Two identical fuzzy controllers with two inputs (the signal error and its derivative) are used jointly with a PI controller. The detailed description of the conceived fuzzy logic controllers is presented in the next section.

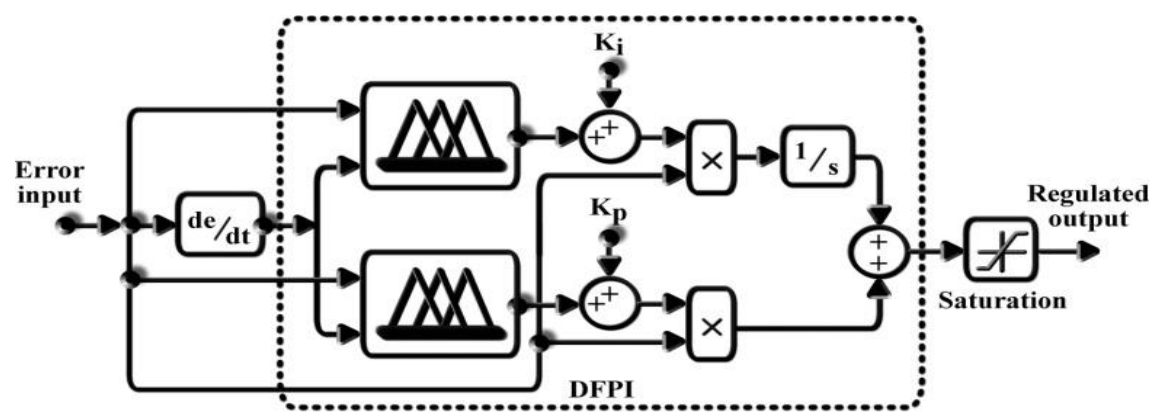

Figure 3. The schematic diagram of the DFPI controller

For extracting the reference signal is performed by applying the PSF algorithm which scheme is displayed in Figure 4 [17], [19]. The principle is to force the source current to be in phase with the positive sequence of the voltage source fundamental frequency. Thus, this algorithm makes it possible the compensation of the power factor as well as the compensation of the harmonic currents. The reference currents can be derived from (1).

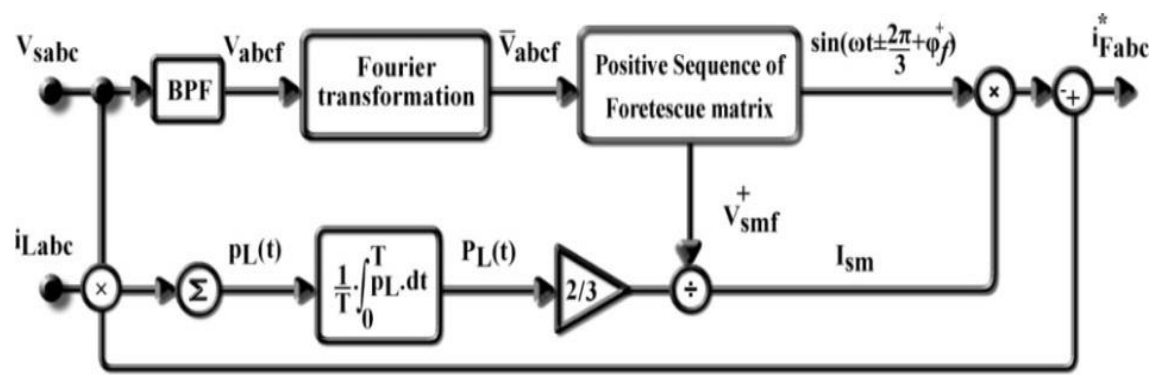

Figure 4. Principle of the PSF algorithm for extracting the reference currents

$$
\left[\begin{array}{c}
\mathrm{i}_{\mathrm{Fa}}^{*} \\
\mathrm{i}_{\mathrm{Fb}}^{*} \\
\mathrm{i}_{\mathrm{Fc}}^{*}
\end{array}\right]=\left[\begin{array}{c}
\mathrm{i}_{\mathrm{La}} \\
\mathrm{i}_{\mathrm{Lb}} \\
\mathrm{i}_{\mathrm{Lc}}
\end{array}\right]-\mathrm{I}_{\mathrm{sm}} \cdot\left[\begin{array}{c}
\sin \left(\omega \mathrm{t}+\varphi_{\mathrm{f}}^{+}\right) \\
\sin \left(\omega \mathrm{t}-2 \pi / 3+\varphi_{\mathrm{f}}^{+}\right) \\
\sin \left(\omega \mathrm{t}+2 \pi / 3+\varphi_{\mathrm{f}}^{+}\right)
\end{array}\right]
$$


With:

$$
\mathrm{I}_{\mathrm{sm}}=\frac{2}{3} \cdot \frac{\mathrm{P}_{\mathrm{L}}}{\mathrm{V}_{\mathrm{smf}}^{+}}
$$

The subscript ' $\mathrm{f}$ ' designates the fundamental component while the superscript indicates the positive sequence. More details about the PSF algorithm are available in [19].

\section{Conception of the Fuzzy Logic Controllers}

The specifications of the fuzzy controller dedicated to regulate the SAPF DC voltage (Vdc) are grouped in Table 1 whereas those of the AC current (iF) are summarized in Table 2. Note that the used fuzzy system is based on Mamdani concept which was as an attempt to control a steam engine and boiler combination by synthesizing a set of linguistic control rules obtained from experienced human operators [22]. Figures 5 and 6 show the established fuzzy systems membership functions and mechanism of inference.

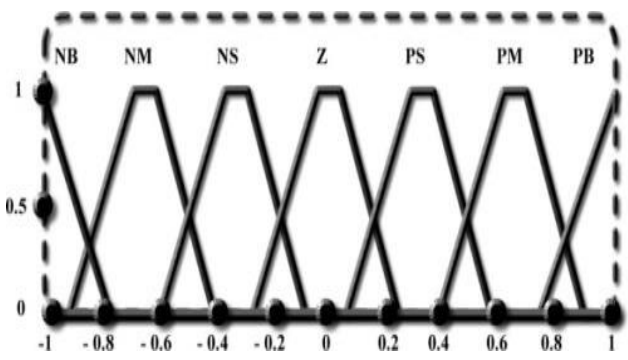

(a)

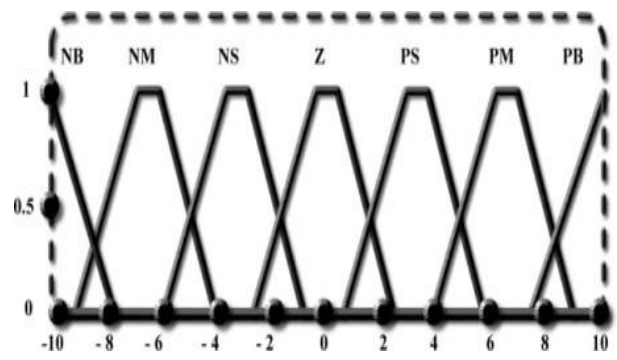

(b)

Figure 5. Vdc DFPI Controller Membership Functions of (a) Input Variable e \& $\Delta$ e, (b) Output Variable Vdc_cor

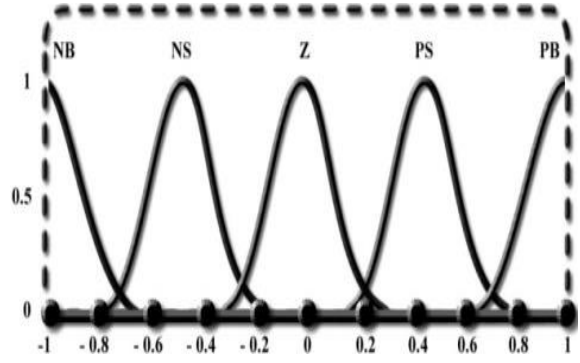

(a)

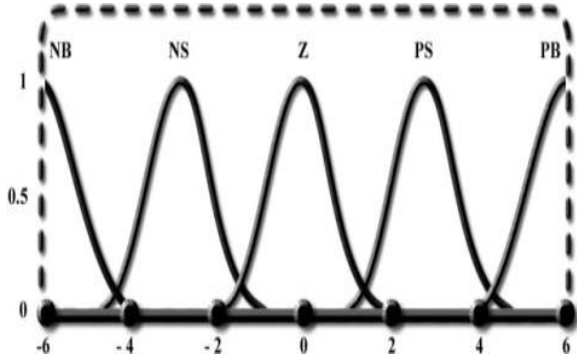

(b)

Figure 6. Current DFPI Controller Membership Functions of (a) Input Variable e \& $\Delta$ e, (b) Output Variable iF_cor

Table 1. Specifications of the Fuzzy Controller Dedicated to the DC Voltage

\begin{tabular}{ccc}
\hline & Type of membership function & Number of membership function \\
\hline The error 'e' & Trapezoidal & 7 \\
The error derivative 'de' & Trapezoidal & 7 \\
The output ' $\Delta \mathrm{e}$ ' & Trapezoidal & 7 \\
Methode of defuzzification & & Bisector \\
\hline
\end{tabular}

Table 2. Specifications of the Fuzzy Controller Dedicated to the AC Current

\begin{tabular}{ccc}
\hline & Type of membership function & Number of membership function \\
\hline The error 'e' & Gaussian & 5 \\
The error derivative 'de' & Gaussian & 5 \\
The output ' $\Delta e^{\prime}$ & Gaussian & 5 \\
Methode of defuzzification & & Bisector \\
\hline
\end{tabular}


The inference mechanisms of both fuzzy systems carry out the following rules recorded in Tables 3 and 4 which refer to the fuzzy systems applied to regulate $V_{d c}$ and $i_{F}$ respectively. The first fuzzy system defines 49 rules while the second one outputs 25 rules. Here the number of rules is fixed by the product of the number of the inputs membership functions.

Table 3. Rules of the Fuzzy Logic Controller of Vdc

\begin{tabular}{cccccccc}
\hline$\Delta$ e/e & NB & NM & NS & Z & PS & PM & PB \\
\hline NB & PB & PB & PB & PB & PM & PS & Z \\
NM & PB & PB & PB & PM & PS & Z & Z \\
NS & PB & PM & PS & PS & Z & NS & NM \\
Z & NM & NS & Z & Z & Z & NS & NM \\
PS & NM & NS & Z & PS & PS & PM & PB \\
PM & Z & Z & PS & PM & PM & PB & PB \\
PB & Z & PS & PB & PB & PB & PB & PB \\
\hline
\end{tabular}

Table 4. Rules of Fuzzy Logic Controller of iF

\begin{tabular}{cccccc}
\hline$\Delta \mathrm{e} / \mathrm{e}$ & $\mathrm{NB}$ & $\mathrm{NS}$ & $\mathrm{Z}$ & $\mathrm{PS}$ & $\mathrm{PB}$ \\
\hline NB & PB & NB & NS & NS & Z \\
NS & NB & NS & NS & Z & PS \\
Z & NS & NS & Z & PS & PS \\
PS & NS & Z & PS & PS & PB \\
PB & Z & PS & PS & PB & PB \\
\hline
\end{tabular}

\section{Dimensioning of the Pi Controllers}

This section is dedicated to the sizing of both PI regulators coefficients. For that the method of the Bode diagram is adopted [20]-[21].

\subsection{AC Side of the SAPF Current PI Regulator}

Figure 7 represents a zoom of small part of the modulating signal and the carrier signal in the top and the output voltage [20]. The mean value of the output voltage is given as:

$$
\left\langle\mathrm{V}_{\mathrm{F}}\right\rangle=V_{d c} \cdot(2 \alpha-1), \text { and } \alpha=\frac{A_{p}+A_{m}}{2 \cdot A_{p}}
$$

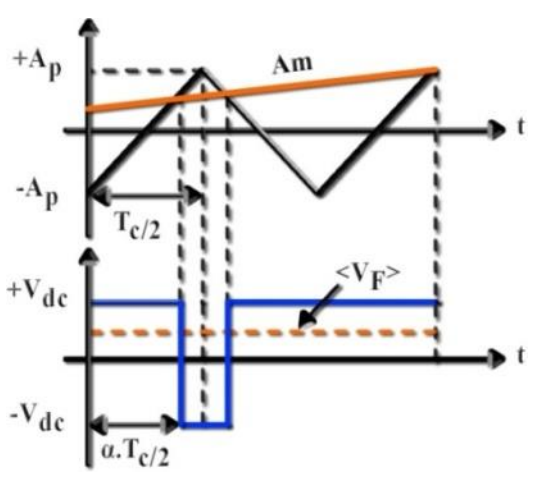

Figure 7. the curves of the output voltage and the modulating signal

where; $\left\langle\mathbf{V}_{\mathbf{F}}\right\rangle$ is the mean vale of the SAPF output voltage, $\alpha$ is the duty cycle,

$\mathbf{A}_{\mathbf{p}}$ and $\mathbf{A}_{\mathbf{m}}$ are respectively the carrier and the modulating signal amplitudes, $\mathbf{T}_{\mathbf{c}}$ is the period of the carrier signal.

Then the transfer function of the system is expressed by: 
$\operatorname{OLTF}_{\text {sys }}(\mathbf{p})=\frac{i_{\mathrm{F}}}{A_{\mathrm{m}}}=\frac{\left\langle V_{\mathrm{F}}\right\rangle}{A_{\mathrm{m}}} \cdot \frac{\mathrm{i}_{\mathrm{F}}}{\left\langle V_{\mathrm{F}}\right\rangle}$

Figure 8 shows a customary flow chart to be followed for performing the sizing of $\mathrm{Ki}$ and $\mathrm{Kp}$ whatever the appliance.

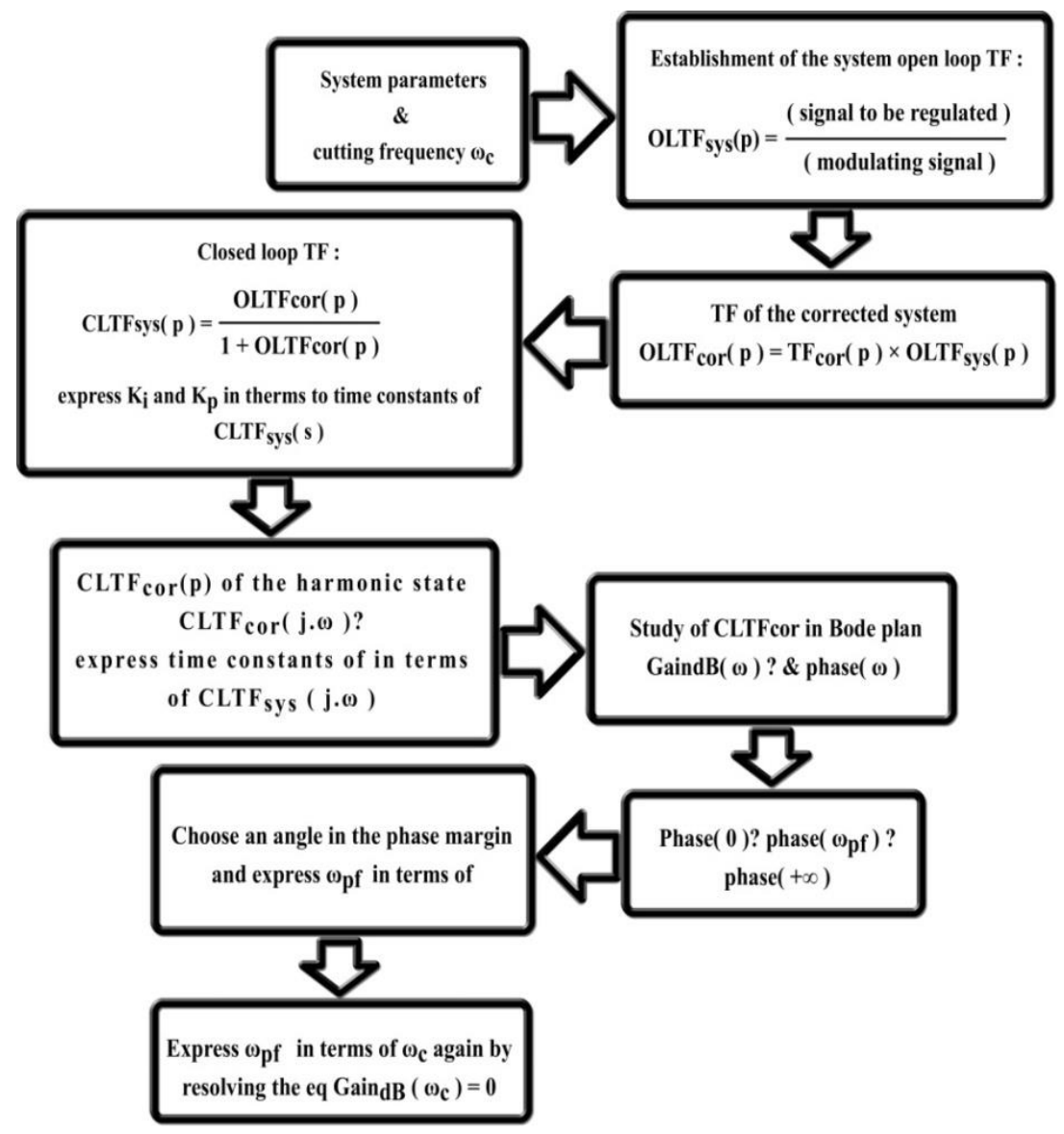

Figure 8. Flow Chart of the applied algorithm for the design of the PI following Bode diagram

From (3) one can F deduce that:

$$
\frac{\left\langle V_{F}>\right.}{A_{m}}=\frac{V_{d c}}{A_{p}}
$$

Assuming an amount of voltage drop in the output filter inductance of $20 \%$ of the APF output voltage mean value, then:

$$
\frac{\mathrm{i}_{\mathrm{F}}}{\left\langle\mathrm{V}_{\mathrm{F}}\right\rangle}=\frac{\mathbf{2 0} \%}{\mathrm{~L}_{\mathrm{f}} \cdot \mathbf{p}}
$$

Consequently

Where

$$
\operatorname{OLTF}_{\text {sys }}(p)=\frac{1}{\text { a.p }}
$$

$$
\mathbf{a}=\frac{\mathbf{L}_{\mathbf{f}} \cdot \mathbf{A}_{\mathbf{p}}}{20 \% \cdot \mathbf{V}_{\mathbf{d c}} \cdot \mathbf{L}_{\mathbf{f}} \cdot \mathbf{A}_{\mathbf{p}}}
$$


The transfer function of the corrected system using a PI regulator is then:

$$
\operatorname{OLTF}_{\text {cor }}(p)=\frac{1+\frac{K_{p}}{K_{i}} \cdot p}{a \cdot \frac{1}{K_{i}} p^{2}}=\frac{1+\tau_{1} \cdot p}{\tau_{2} \cdot p^{2}}
$$

With:

$$
\tau_{1}=\frac{\mathrm{K}_{\mathrm{p}}}{\mathrm{K}_{\mathrm{i}}} \text { and } \tau_{2}=\frac{\mathrm{a}}{\mathrm{K}_{\mathrm{i}}}
$$

In the harmonic state, the $\operatorname{OLFT}_{\text {cor }}(\mathbf{j} . \boldsymbol{\omega})$ is expressed by:

$$
\operatorname{OLFT}_{\operatorname{cor}}(\mathbf{j} . \omega)=\frac{1+\mathrm{j} \cdot \frac{\omega}{\omega_{1}}}{\mathrm{j}^{2} \cdot\left(\frac{\omega}{\omega_{0}}\right)^{2}}
$$

With:

$$
\omega_{1}=\frac{1}{\tau_{1}} \text { and } \omega_{0}=\frac{1}{\sqrt{\tau_{2}}}
$$

The $\mathbf{C L T F}_{\text {cor }}$ is given by : $\quad \mathbf{C L T F}_{\text {cor }}=\frac{\mathbf{O L T F}_{\text {cor }}}{1+\mathbf{O L T F}_{\text {cor }}}$

Then:

$$
\begin{aligned}
& \operatorname{CLTF}_{\text {cor }}(p)=\frac{1+\tau_{1} \cdot \mathrm{p}}{1+\tau_{1} \cdot \mathrm{p}+\tau_{2} \cdot \mathrm{p}^{2}} \\
& \operatorname{CLTF}_{\text {cor }}(\mathrm{j} \cdot \omega)=\frac{1+\mathrm{j} \cdot \frac{\omega}{\omega_{1}}}{1+\mathrm{j} \cdot \frac{\omega}{\omega_{1}}+\mathrm{j} \cdot\left(\frac{\omega}{\omega_{0}}\right)^{2} \cdot p^{2}}
\end{aligned}
$$

By studying the $\operatorname{Gain}_{\mathbf{d B}}\left(\boldsymbol{\omega}_{\mathbf{c}}\right)$ and the Phase $(\omega)$ of the $\operatorname{CLTF}_{\mathbf{c o r}}(\mathbf{j} . \boldsymbol{\omega})$ in Bode plan, one can extract the gain margin and the phase margin. Then the particular angular frequencies $\omega$ pf(i.e. $\omega 0$ and $\omega 1$ ) will be obtained by resolving the following equations:

$$
\operatorname{Gain}_{\mathrm{dB}}\left(\omega_{\mathrm{c}}\right)=\mathbf{0}
$$

$\operatorname{Phase}\left(\omega_{\mathrm{c}}\right)=$ angle $\epsilon$ phase margin

Where $\omega_{c}$ is the angular cutting frequency that should be chosen so that the passing band of the $\mathrm{PI}$ is inferior to the cutting frequency to ensure a good follow of iF to its reference. Practically the passing band is limited to the quarter of the cutting frequency [20] so:

$$
\omega_{c}=\frac{1}{4} \cdot 2 \cdot \pi \cdot f_{c}
$$

\subsection{Side of the APF Voltage PI Regulator}

The transfer function of the system is expressed by [20],

$$
\operatorname{OLTF}_{\text {sysv }_{\mathrm{dc}}}(\mathbf{p})=\frac{\mathrm{v}_{\mathrm{dc}}}{\mathrm{i}_{\mathrm{Fam}}}
$$

With: $\mathbf{i}_{\mathrm{Fam}}$ is the maximum value of the SAPF active current.

By ignoring the switching losses in the active filter and in the output filter, the energy is the same in both $\mathrm{DC}$ and $\mathrm{AC}$ sides. Thus the variation in the stored energy in the capacitor $\mathbf{C}_{\mathbf{d c}}$ for small changes in $\mathbf{V}_{\mathbf{d c}}$ around its reference voltage $\mathbf{V}_{\mathbf{d c}}^{*}$ is deduced from:

$$
d E_{d c}=C_{d c} \cdot V_{d c}^{*} \cdot \frac{d}{d t} V_{d c} \cdot d t=P_{a c} \cdot d t
$$


where: $P_{a c}$ is the active power in the APF AC side and which is given by:

$$
P_{\text {ac }}=3 \cdot V_{\text {FaRMS }} \cdot \mathbf{i}_{\text {FaRMS }}=\frac{3}{\sqrt{2}} \cdot V_{\text {FaRMS }} \cdot \mathbf{i}_{\text {Famax }}
$$

With

$\mathbf{V}_{\mathrm{FaRMS}}, \mathbf{i}_{\mathrm{FaRMS}}$ are the RMS values of the active components of $\mathrm{V}_{\mathrm{F}}$ and $\mathrm{i}_{\mathrm{F}}$ respectively.

Thus:

With:

$$
\operatorname{OLTF}_{\text {sysV }_{\mathrm{dc}}}(\mathbf{p})=\frac{3 \cdot \mathrm{V}_{\mathrm{FaRMS}}}{\sqrt{2} \cdot \mathrm{C}_{\mathrm{dc}} \cdot \mathbf{V}_{\mathrm{dc}}^{*} \cdot \mathbf{p}}=\frac{1}{\mathrm{~b} \cdot \mathbf{p}}
$$

$$
\mathbf{b}=\frac{\sqrt{2} \cdot \mathbf{C}_{\mathrm{dc}} \cdot V_{\mathrm{dc}}^{*}}{3 \cdot V_{\mathrm{FaRMS}}}
$$

It is obvious from (21) that the extracted OLTF is based on an integrator as for that of the current expressed in (7). Consequently, the design of the PI coefficients can be done similarly those of the current regulator presented in section $A$.

\section{Results \& Discussion}

The model of Figure 1 is simulated using MATLAB/Simulink, by applying the parameters shown in Table 5.

Table 5. Simulation Parameters

\begin{tabular}{ll}
\hline \multicolumn{1}{c}{ Parameter } & \multicolumn{1}{c}{ Value } \\
\hline AC supply line-to-line voltage and frequency & $380 \mathrm{~V}, 50 \mathrm{~Hz}$ \\
Supply impedance & $\mathrm{Rs}=0.07 \Omega, \mathrm{Ls}=0.25 \mathrm{mH}$ \\
Rectifier load 1 & $\mathrm{RL}=10 \Omega, \mathrm{LL}=50 \mathrm{mH}$ \\
Rectifier load 2 & $\mathrm{RL}=5 \Omega, \mathrm{LL}=25 \mathrm{mH}$ \\
Time of variation & $0.25 \mathrm{~s}$ \\
Output-filter impedance & $\mathrm{Rf}=10 \mathrm{~m} \Omega, \mathrm{Lf}=0.7 \mathrm{mH}$ \\
Upstream-filter impedance & $\mathrm{Rc}=0.387 \Omega, \mathrm{LC}=0.3 \mathrm{mH}$ \\
DC link capacitor and resistance & $\mathrm{Cdc}=3.1 \mathrm{mF}, \mathrm{Rdc}=64.5 \Omega$ \\
DC link reference voltage & $\mathrm{V}_{\mathrm{dc}}^{*}=550 \mathrm{~V}$ \\
The carrier based PWM properties : Ap, fp & $6.25 \mathrm{~A}, 5 \mathrm{kHz}$ \\
Current PI Coefficients: a, fc, phase & $25.88 \mu \mathrm{ss}, 5 \mathrm{kHz}, \pi / 3 \mathrm{rad}$ \\
$D C$ voltage PI Coefficients: $b, f c$, phase & $3.7 \mathrm{~ms}, 20 \mathrm{~Hz}, \pi / 3 \mathrm{rad}$ \\
\hline
\end{tabular}

Figure 9 shows the Bode diagrams for both gains and phase margins of the AC current and DC voltage regulators of the SAPF. According to these diagrams one can confirm that the first regulator cuts at $\frac{2 . \pi .10^{4}}{4} \mathrm{rad} / \mathrm{s}$ while the second one cuts at $2 . \pi .20 \mathrm{rad} / \mathrm{s}$. Besides it is obvious that the phase margin for both regulators is $\pi / 2$ rad. The PI coefficients values carriedout using the method of Bode diagram are reported in Table 6.

Table 6. PI regulators coefficients

\begin{tabular}{ccccc}
\hline & $\omega_{1}=\omega_{c} / \sqrt{\mathbf{2}}$ & $\boldsymbol{\omega}_{2}=\mathbf{2 .} \boldsymbol{\omega}_{c} / \tan (\boldsymbol{\pi} / \mathbf{3})$ & $\mathbf{K}_{\mathbf{i}}$ & $\mathbf{K}_{\mathbf{p}}$ \\
\hline $\mathrm{PI} \mathrm{i}_{\mathrm{F}}$ & $5553.6 \mathrm{rad} / \mathrm{s}$ & $9069 \mathrm{rad} / \mathrm{s}$ & 798.37 & 0.088 \\
$\mathrm{PI} \mathrm{V}_{\mathrm{dc}}$ & $88.86 \mathrm{rad} / \mathrm{s}$ & $145 \mathrm{rad} / \mathrm{s}$ & 28.93 & 0.2 \\
\hline
\end{tabular}




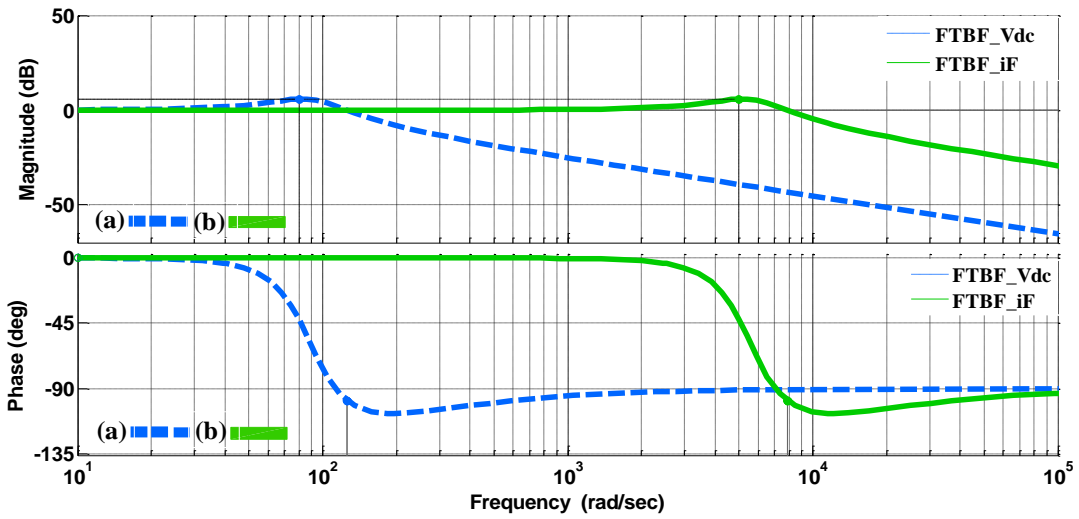

Figure 9. Bode diagrams the closed loop transfer functions of (a) iF_PI regulator, (b) Vdc_PI regulator

Figure 10 displays the source current waveform (Figure 10(a)), its harmonic spectrum (Figure 10(b)) limited to the $25^{\text {st }}$ orders since they are the most obstructive) and the stacked curves of source current and voltage (Figure 10(c)) before applying the shunt active power filtering. The display is limited to phase a since the two other phases are similar but shifted by $-2 \pi / 3$ rad and $+2 \pi / 3$ rad respectively. The $\operatorname{THD}$ (is) $23,15 \%$ which does not meet with the international standards restrictions.

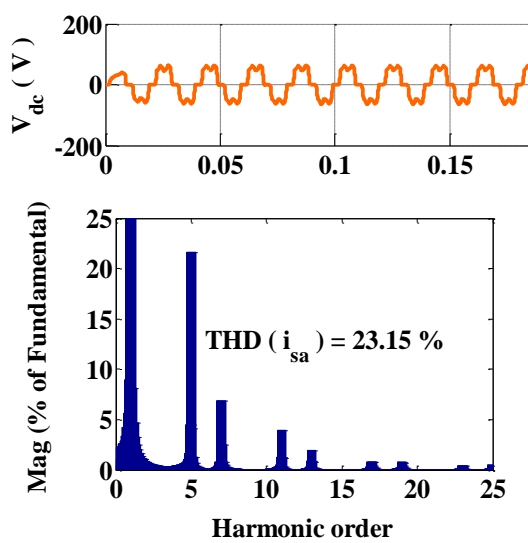

(b )

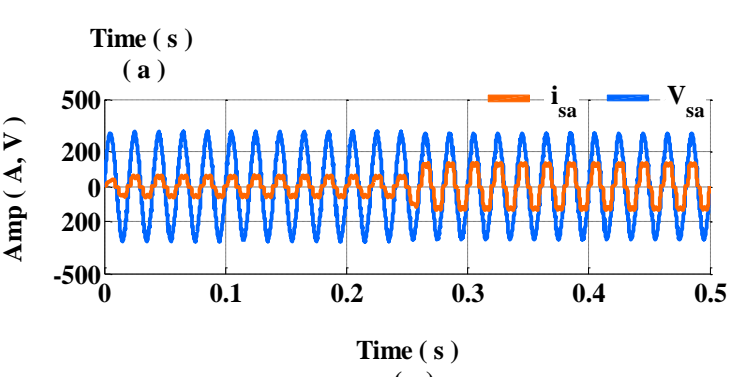

(c)

Figure 10. Results Before Starting the Operation of the SAPF (a) The Source Current isa (b) Harmonic Spectrum of isa and (c) Vsa and isa

After applying the SAPF based on the two DFPI controllers using the PSF algorithm for the reference signal generation the results presented in Figure 11 demonstrate a potential improvement in the source current waveform (Figure 11(b)) and a near-perfect clean of its harmonic spectrums of both source current and voltage (Figure 11(d) and Figure 11(e)) with a reduced $\mathrm{THD}$ (is) of $1.50 \%$ and an acceptable $\mathrm{THD}(\mathrm{Vs})$ of $3.65 \%$ although a disturbed waveform (Figure 11(c)) due mainly to the small value chosen for $L_{F}$. Figure 11(a) shows the result brought by the DC voltage DFPI regulator where a perfect regulation can be observed even at the moment of the load variation. Indeed after passing by a small transient state corresponding to the time of load change $(0.25 \mathrm{~s})$ the $\mathrm{DC}$ voltage returns to its reference $(550 \mathrm{~V})$. 

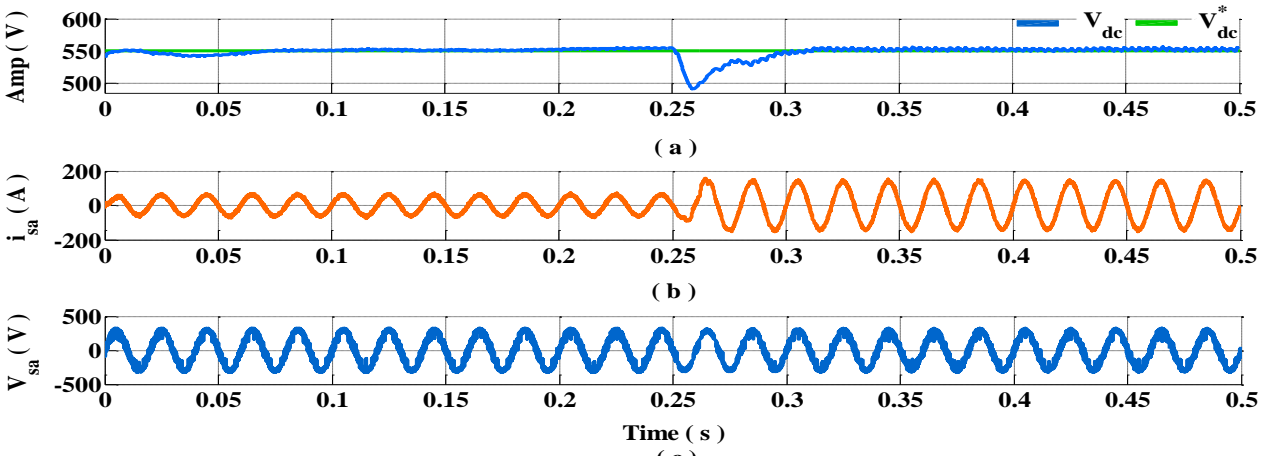

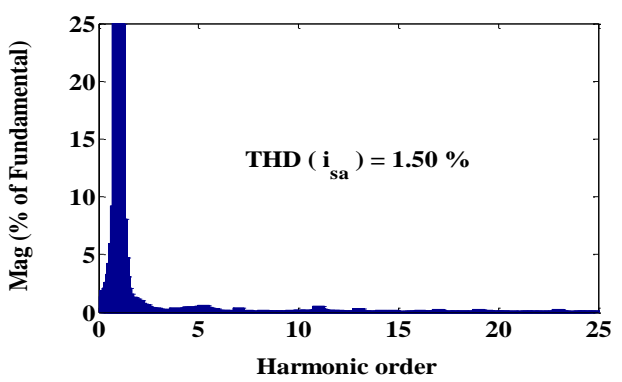

(d)

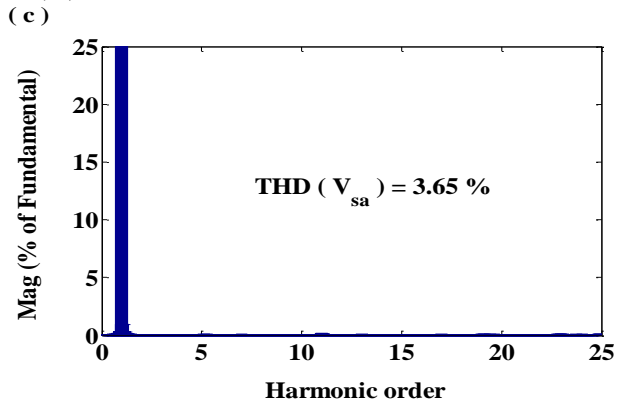

(e)

Figure 11. Results after applying the DFPI controller associated to the PSF algorithm, (a) Vdc and Its reference, (b) isa, (c) Vsa, (d), isa harmonic spectrum (e), Vsa harmonic spectrum

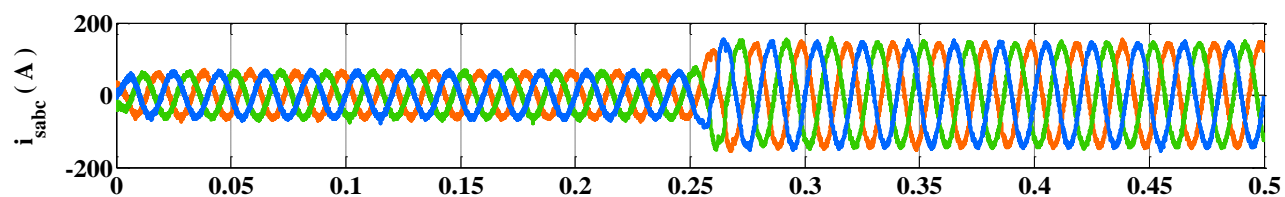

( a )

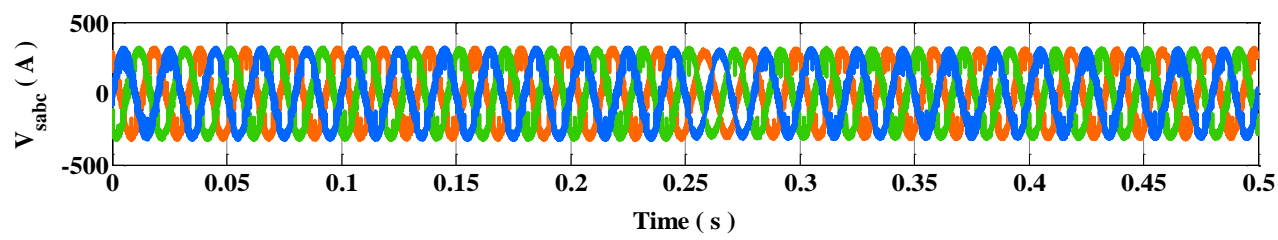

(b)

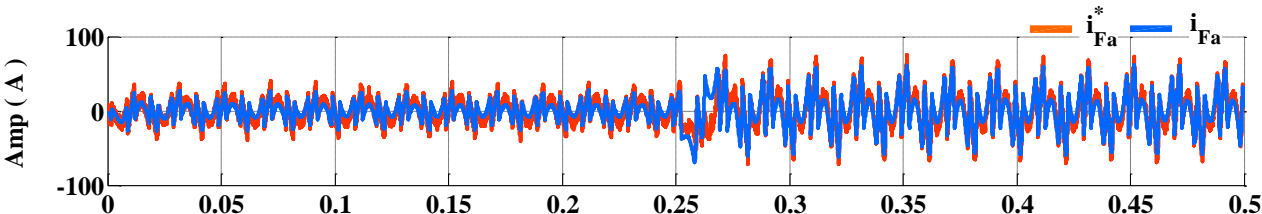

(c)

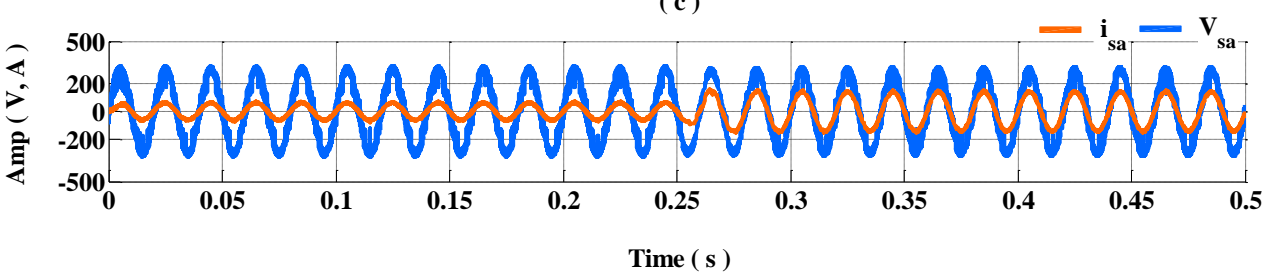

(d)

Figure 12. Results of (a) three-phase compensation of source current (b) three-phases source voltages, (c) the compensating current following its reference, (d) source voltage and current of the same phase 
Figure 12 illustrates the result concerning the three-phase quantities where can conclude about the balance of the source current system (Figure 12(a)) as well as for the source voltage system (Figure 12(b)). Figure 12(c) depicts the compensating current following perfectly its reference carried out by the PSF algorithm. Finally, Figure 12(d) proves a near-unity power factor and then a compensated reactive power seen that both source voltage and current are almost in phase. Finally, the power factor value as well as the imbalance rates of the threephase source voltage and current obtained after the simulation are recorded in Table 7.

Table 7. The Obtained Power Factor and Imbalance Rates

\begin{tabular}{ccc}
\hline Power factor & Voltage imbalance rate & Current imbalance rate \\
\hline $\mathrm{FP}=0.9869$ & $0.0241 \%$ & $0.1193 \%$ \\
\hline
\end{tabular}

\section{Conclusion}

In a previous work the pair (DFPI, PSF) has shown satisfactory results for the DC voltage bus regulation. In this work the couple (DFPI, PSF) is also applied of the control of the SAPF output current. The study provides explanations about the conception of the fuzzy controllers as well as a flow chart for dimensioning a PI in the general case. The presented work was verified by computer simulations performed under MATLAB/Simulink. The results have proven the effectiveness and robustness of DFPI controller to regulate the DC voltage and AC current of the SAPF. Therefore, the obtained THD(is) and THD(Vs) are conforming to the curbs fixed by the standards. Moreover, the reactive power is perfectly compensated since the obtained power factor is very near to the unity. Finally, one can conclude that the power quality can be improved at very satisfactory level by adopting the couple (DFPI, PSF).

\section{References}

[1] S Chattopadhyay, et al. Electric power quality. Springer. 2010.

[2] H Akagi. The state-of-the-art of active filters for power conditioning. European Conference on Power Electronics and Applications. 2005: 1-15.

[3] K Sozański. Digital signal processing in power electronics control circuits. Springer. 2013.

[4] M Wang, et al. Historical review of parallel hybrid active power filter for power quality improvement. TENCON. 2015: 1-6.

[5] LH Tey, et al. Improvement of power quality using adaptive shunt active filter. IEEE Transaction on Power Delivery. 2005; 2: 1558-1568.

[6] Z Salam, et al. Harmonics mitigation using active power filter: A technological review. ELEKTRIKA. 2006; 2: 17-26.

[7] $\mathrm{Y} \mathrm{Pal}$, et al. Review of compensating type custom power devices for power quality improvement. POWERCON. 2008: 1-8.

[8] B Singh, et al. Power Quality: Problems and Mitigation Techniques. John Wiley and Sons Ltd, Chapter 9. 2015: 397-451.

[9] M Routimo, et al. Comparison of voltage-source and current source shunt active power filters. IEEE Transaction on Power Electronics. 2007; 2: 636-643.

[10] K Steela, BS Rajpurohit. A survey on active power filters control strategies. IEEE 6th India International Conference on Power Electronics. 2014: 1-6.

[11] LA Moran, et al. A three-phase active power filter operating with fixed switching frequency for reactive power and current harmonic compensation. IEEE Transactions on Industrial Electronics. 1994; 4: 402-408.

[12] P Dey, et al. Performance evaluation of reference current extraction methods for hybrid active power filter. International Conference on Informatics. Electronics and Vision.b2013: 1-6.

[13] K Vardar, E Akpinar. Evaluation of reference current extraction methods for DSP implementation in active power filters. Electric Power Systems Research. 2009; 10: 1342-1352.

[14] T Demirdelen, et al. Review of hybrid active power filter topologies and controller. POWERENG. 2013: 587-592.

[15] SK Khadem, et al. A review of parallel operation of active power filters in the distributed generation system. 14th European Conference on Power Electronics and Applications. 2011: 1-10.

[16] N Elhaj, et al. Contribution of a shunt active power filter control using double fuzzy Pl controller. 16th International Power Electronics and Motion Control Conference and Exposition. 2014: 1177-1182.

[17] N Elhaj, et al. An improved double fuzzy PI controller for shunt active power filter DC bus regulation. International Journal of Power Electronics and Drive System. 2015; 2: 337-347. 
[18] D Wang, et al. Hybrid active power filter DC Bus control based on double fuzzy control. 2nd International Conference on Computational Intelligence and Natural Computing Proceedings, 1. 2010: 287-290.

[19] GW Chang, TC Shee. A novel reference compensating current strategy for shunt active power filter control. IEEE Transaction on Power Delivery. 2004; 4: 1751-1758.

[20] P Ladoux, G Ollé. Compensator of harmonics and reactive power, Compensateur d'harmoniques et de puissance réactive. Publication RESELEC. 2002: 1-45.

[21] A Chaoui, et al. IP controlled three-phase shunt active power filter for power improvement quality. 32nd Conference on IEEE Industrial Electronics. 2006: 2384-2389.

[22] $\mathrm{EH}$ Mamdani and S Assilian. An experiment in linguistic synthesis with a fuzzy logic controller. International Journal of Man-Machine Studies. 1975; 1: 1-13. 